\title{
The unmet provision of allergy services in Hong Kong impairs capability for allergy prevention - implications for the Asia Pacific region.
}

\author{
Tak-hong Lee, ${ }^{1 *}$ Ting-fan Leung, ${ }^{2}$ Gary Wong, ${ }^{2}$ Marco Ho, ${ }^{3}$ Jaime Rosa Duque, ${ }^{3}$ Philip Hei Li, ${ }^{4}$ Chak-sing Lau, ${ }^{4}$ Wai-fan Lam, \\ Adrian Wu, Eric Chan, ${ }^{6}$ Christopher Lai, ${ }^{5}$ Yu-lung Lau ${ }^{3}$
}

\begin{abstract}
There is a high and rising prevalence of many allergic diseases in the Asia Pacific, including Hong Kong, which is unmatched by a commensurate provision of clinical allergy services. In the last 3 years, the allergy profile in Hong Kong has increased due to greater public engagement and more frequent educational activities, scientific outputs and publication of local guidelines on allergy prevention, diagnosis and treatment. Two new drug allergy clinics have been established in public hospitals, and for the first time in 20 years, Hong Kong has its first trainee in adult allergy. The current ratio of allergists per head of population has improved slightly from 1:1.46 (in 2014) to 1:1.17 million, but it is still low compared to many countries. The Hong Kong community is well supported by allergy-related professional societies and patient organisations. While the recent developments indicated some progress, Hong Kong remains inadequately equipped to take advantage of the new discoveries that may prevent allergic diseases and improve public health. There are also 5-fold more paediatric allergists than adult allergists per head of population. If this unbalance remains uncorrected, continuing care for allergic children as they grow into adulthood will be an increasing problem. This review provides recommendations to improve allergy service provision and training, including the creation of Centres of Excellence in allergy to drive the growth of this specialty.
\end{abstract}

Keywords: Hong Kong; Asia Pacific; allergy services; training; epidemiology; prevention; public health; allergy centre

\section{From:}

${ }^{1}$ Allergy Centre, Hong Kong Sanatorium and Hospital, Happy Valley, Hong Kong

${ }^{2}$ Department of Paediatrics, The Chinese University of Hong Kong, Prince of Wales Hospital, Shatin, Hong Kong

Department of Paediatrics and Adolescent Medicine, Queen Mary Hospital, The University of Hong Kong, Pokfulam, Hong Kong

${ }^{4}$ Division of Rheumatology and Clinical Immunology, Department of Medicine, The University of Hong Kong, Pokfulam, Hong Kong

\section{Introduction}

In 2015, the Hong Kong Allergy Alliance highlighted the rising trend of allergic diseases in Hong Kong and the heavy burden placed on local clinical services in the face of a relative paucity of allergy trained doctors and specialists. ${ }^{1}$ It was estimated that there was only one allergy specialist for 1.46 million people, which was fewer than in many countries. ${ }^{2}$

Training in Paediatric Immunology and Infectious Diseases (PIID) in Hong Kong, which included allergy, was robust but there had not been any local trainee in adult Immunology and Allergy for nearly two decades. It was recommended that two new multi-professional Allergy Centres should be created under a hub-and-spoke model in the public sector. ${ }^{1}$

This review summarises some key discoveries on allergy prevention that could impact Hong Kong and the Asia Pacific.

\author{
${ }^{5}$ Private practice, Hong Kong \\ ${ }^{6}$ Department of Pathology, Queen Mary Hospital, Pokfulam, Hong \\ Kong \\ Corresponding author: \\ Tak-hong Lee \\ Allergy Centre, 9/F Li Shu Pui Block, Hong Kong Sanatorium and \\ Hospital, 2 Village Road, Hong Kong \\ Email: takhong.lee@hksh.com
}

Progress in allergy service provision and training in Hong Kong is updated and case histories are presented to illustrate the continuing challenges. The findings suggest that despite some progress, Hong Kong is currently still unlikely to be able to fully deliver the marked changes required to implement international guidelines on preventing allergies. ${ }^{3-6}$ Hong Kong's experience may parallel those of other Asian Pacific countries, many of which face similar challenges.

\section{What is new in allergy prevention that could impact on Hong} Kong and the rest of the Asian Pacific region?

Asia Pacific is densely populated and is undergoing rapid urbanisation. With the loss of protective factors associated with a rural environment and emergence of risk factors 
associated with adopting a western lifestyle, the rising prevalence of allergic disorders in the region will likely continue to escalate in the next few decades, ${ }^{1,7}$ thereby posing a severe burden on health services unless a preventative strategy can be implemented.

A number of early life modulators may play a central role in allergic sensitisation ${ }^{8-11}$ and they could be manipulated to prevent allergies. The World Health Organisation recommends exclusive breastfeeding of infants in their first six months of life, ${ }^{12}$ and many international guidelines had previously also recommended delaying introduction of allergenic foods such as egg, fish, shellfish, nuts, and wheat-based foods during infancy. ${ }^{13-15}$ Thus, the recent publication of Learning Early About Peanut (LEAP) data was transformational because the study found early peanut introduction starting at 4-11 months of life in high-risk infants imparted a significant protective effect against the development of peanut allergy. ${ }^{16}$ Based on such important, groundbreaking results, most international guidelines on infant feeding have already been revised. ${ }^{4-6}$

The LEAP study prompted world-wide interest in whether early introduction of other foods could also prevent allergy development. Perkin et al studied more than 1,300 infants who were randomly assigned to the introduction of 6 allergenic foods (peanut, cooked egg, cow's milk, sesame, whitefish and wheat) or to the standard UK recommendation of exclusive breast feeding to 6 months. ${ }^{17}$ The children were assessed regularly until 3 years old for development of allergies to one or more of the 6 foods. While there was no significant difference between the two groups in the intention-to-treat analysis, the per-protocol analysis showed a significantly lower percentage of children in the early introduction group that developed any food allergy. ${ }^{17,18}$ A benefit was also seen for preventing peanut allergy and egg allergy.

Hen's egg allergy is one of the commonest forms of food allergy and early-life sensitisation to egg is strongly associated with sensitisation to aeroallergens in preschool years. The two-step egg introduction for prevention of egg allergy in high-risk infants with eczema (PETIT) study tested whether early egg introduction could prevent egg allergy, but it also instituted aggressive treatment of eczema before and during feeding of allergenic food. 147 infants aged 4-5 months with eczema were randomised to have early introduction of egg or placebo. ${ }^{19}$ The clinical trial was terminated early because the results of the scheduled interim analysis of 100 participants showed that infants with early egg introduction had significantly fewer egg allergy (five [8\%] versus 23 [38\%] in the placebo group; risk ratio 0.222 ). The subjects did not experience increased risk of egg-induced allergic reactions. It was concluded that the introduction of heated egg in a stepwise manner along with aggressive eczema treatment was safe and efficacious to prevent egg allergy in high-risk infants.

Three studies on early egg introduction at 4-6 months of age failed to replicate its benefit for egg allergy in Caucasian babies. ${ }^{20-22}$ In addition, $8.5 \%$ of infants who received egg early experienced significant allergic symptoms upon egg ingestion. ${ }^{20}$ The inclusion of an aggressive eczema treatment strategy distinguished the PETIT study from the other clinical trials and thus this was a likely explanation for the difference in results. ${ }^{23}$ An earlier randomised controlled trial of 118 Japanese neonates had also found eczema to be a significant risk factor for IgE sensitisation to egg white and that eczema development could be substantially reduced with the daily application of an emulsion-type moisturiser during the first 32 weeks of life. ${ }^{24}$

Researchers from Singapore investigated the timing of allergenic food introduction and food allergy outcomes from the Growing Up in Singapore Towards Healthy Outcomes (GUSTO) study. ${ }^{25}$ They found that most of the infants had been introduced to egg, peanut, and shellfish after 10 months of age, but food allergy prevalence was very low between 12 and 48 months of age. There were no significant associations between the timing for introduction of allergenic foods and the development of food allergy.

The increasing numbers of reports on vitamin D deficiency among different North American ${ }^{26}$ and European ${ }^{27}$ populations over the past two decades have stimulated considerable debate on whether vitamin $\mathrm{D}$ deficiency contributes to allergic diseases. A nationwide, cross-sectional survey in 3720 Korean children aged 6-7 years reported the overall prevalence rates of vitamin D insufficiency (20-29 ng/mL) and deficiency $(<20$ $\mathrm{ng} / \mathrm{mL}$ ) to be $64.0 \%$ and $18.4 \%$, respectively. ${ }^{28}$ For a $1 \mathrm{ng} / \mathrm{mL}$ decrease in serum 25-hydroxyvitamin D [25(OH)D] level, the adjusted odds ratios for allergic rhinitis, current atopic dermatitis and skin-prick test positivity were 1.020, 1.027 and 1.013, respectively. Another Korean study found significant relationship between $25(\mathrm{OH}) \mathrm{D}$ levels and the number and degree of food sensitisation and eczema severity. ${ }^{29}$ Vitamin $\mathrm{D}$ deficiency also increased the risk of sensitization to food allergens.

Wang et al published high prevalence rates of vitamin $\mathrm{D}$ deficiency and insufficiency among 826 Hong Kong Chinese children. ${ }^{30}$ They found $25(\mathrm{OH}) \mathrm{D}$ levels to be lower among children with eczema, and there were inverse associations between $25(\mathrm{OH}) \mathrm{D}$ levels and both short-term and long-term indices of eczema severity. Further, vitamin D-deficient patients had higher serum total IgE levels than those with insufficient and physiological 25(OH)D levels. The relationship between vitamin $\mathrm{D}$ and eczema might be modulated by a number of vitamin $\mathrm{D}$ pathway genes. ${ }^{31}$

The high prevalence of vitamin D deficiency was replicated in a population sample of 1,315 Taiwanese children aged 5-18 years who participated in the Prediction of Allergies in Taiwanese Children (PATCH) study. ${ }^{32}$ However, serum $25(\mathrm{OH})$ $\mathrm{D}$ status was not associated with asthma, rhinitis, eczema, atopy and total serum IgE levels after adjustment for potential confounders.

Notwithstanding some conflicting data in the literature, when taken together, there is compelling evidence from large, well-designed clinical trials that early introduction of certain foods, aggressive management of eczema and addressing low vitamin D levels might provide major opportunities for allergy prevention. But even in high-risk infants, any benefits could be food- and population-specific. Further research is required urgently to define the window of opportunity and criteria for intervention including the target populations. Against the background of the rising prevalence of allergic diseases, rapid progress may only be made by a larger network of specialists with expertise in allergy diagnosis and treatment than is currently available in many Asian Pacific countries to 
drive forward discovery science and clinical practice. This will inevitably require dedicated investments of resources but the payback for implementing a successful strategy could be substantial public health gains.

\section{How many allergy specialists are there in Hong Kong?}

There are 4 Immunology and Allergy specialists listed in the Hong Kong Medical Council Specialist Register, ${ }^{33}$ but only two of them practice allergy. Both of them were trained abroad and work in the private sector. Therefore, the ratio of registered adult allergists per head of population in Hong Kong remains around 1:2.8 million head of adult population, ${ }^{34}$ which is exceedingly low.

There are 6 foundation fellows of PIID who spend on average about $40 \%$ of their working week on allergy, so Hong Kong has 2.4 full time equivalent (FTE) specialists in paediatric allergy. Hong Kong has about 1.3 million children under the age of 18 years old, so there is 1 paediatric allergist per 540,000 head of paediatric population. ${ }^{34}$ This is less than the estimate 3 years ago of $1: 460,000^{1}$ as several paediatric allergists who worked full time previously can now only work part time due to increasing administrative and other responsibilities. This has implications for future manpower planning just to maintain the status quo let alone grow the discipline. The difference between numbers of paediatric and adult allergists is very striking and if this situation is not re-balanced, transitional and continuing care for children as they grow into adulthood will become an increasingly major problem.

The number of allergists in Hong Kong will increase by the end of 2017 when two paediatric trainees complete their training in PIID and another immunologist completes her training. However, these graduates can only work part-time in allergy because of the manpower constraints in the public hospital services.

Therefore, we estimate that by the end of 2017, in addition to two full time adult allergists, two immunologists and 8 paediatricians will spend on average about $40 \%$ of their working week in allergy. Assuming Hong Kong has a population of around 7 million, it will have one full time equivalent (FTE) allergist per 1.17 million population, ${ }^{34}$ which is slightly better than the 1:1.46 million figure estimated in $2014,{ }^{1}$ but this would still be inadequate to deliver a robust service.

These figures could have underestimated the available expertise because many patients with allergic diseases are treated by non-allergy specialists and General Practitioners. These doctors are not included in the calculations because the extent of their allergy training cannot be ratified by any existing mechanism. In addition, a few clinicians will have received dual training overseas in Allergy and another specialty, but they are only permitted by the Hong Kong Medical Council to be registered under one specialty, so may have decided to register under a non-allergy specialty. Nevertheless, it is the authors' experience that Hong Kong has very few doctors who have a wide breadth of allergy experience (including but not exclusive to the use of specific allergen immunotherapy, food challenges and specialised allergy testing) who are not already registered as specialists in Immunology and Allergy; Immunology; or PIID. Even if the few doctors who are dually trained are included in the metrics, it would be unlikely to detract from the conclusion that the Hong Kong community is inadequately served by trained allergists.

The authors know of only one published global survey of the ratio of allergists per head of population ${ }^{2}$ (Tables 1 and 2). Hong Kong ranks $6^{\text {th }}$ out of 7 countries in the Asia Pacific, Australia and New Zealand; only Malaysia has fewer allergists. In the rest of the world, Hong Kong ranks $30^{\text {th }}$ out of 36 countries with Ecuador, France, Honduras, Mongolia, Peru and South Africa having less representation. The data need to be updated as the figures (apart from Hong Kong) were published 11 years ago and there could have been significant improvements in some countries, which might make Hong Kong's comparative position even worse.

Hong Kong is among the top 14 countries in the world for gross domestic product per capita ${ }^{35}$ with an average annual growth rate of $2.6 \%$ and prides itself in having an excellent and mature health service. ${ }^{36}$ Therefore, it is both surprising and concerning that Hong Kong, despite its abundance in wealth, is not only insufficiently served by allergy specialists locally, but also very low when compared to the neighbouring region and the rest of the world.

Table 1. Allergists per head of population in Asia pacific, Australia and New Zealand

\begin{tabular}{|l|l|}
\hline Country & Allergists per head of population \\
\hline Australia & $1: 140,000$ \\
\hline \multirow{2}{*}{ Hong Kong } & $1: 1,170,000$ \\
\cline { 2 - 2 } & $\begin{array}{l}\text { Adult } \\
1: 2,800,000\end{array}$ \\
\cline { 2 - 2 } & $\begin{array}{l}\text { Prediatrics } \\
1: 540,000\end{array}$ \\
\hline \multirow{2}{*}{ Japan } & $1: 61,200$ \\
\hline Malaysia & $1: 25,000,000$ \\
\hline New Zealand & $1: 440,000$ \\
\hline Philippines & $1: 66,115$ \\
\hline Thailand & $1: 1,000,000$ \\
\hline
\end{tabular}

Data adapted from ref 2. Permission granted by S Karger AG, Basel. The Hong Kong data is 2017 data whereas the others were extracted from ref 2.

\section{The lack of allergists can create significant problems as illus- trated by the following case histories:}

Case 1: A 53-year old man was recently reviewed at a specialist clinic of a public hospital by an allergy trainee after decades of waiting for an allergist's evaluation. For the past 20 years, he had been admitted to different public hospitals around Hong Kong for idiopathic anaphylaxis. He had first experienced urticaria and facial angioedema about 20 years ago while rushing his daughter to school after eating bread for breakfast. Since then, he has experienced more than 10 similar episodes of varying severity after eating different types of foods, but no consistent allergens could be identified. His most severe reaction occurred when he collapsed while 
Table 2. Allergists per head of population rest of world

\begin{tabular}{|c|c|c|c|}
\hline Country & Allergists per head of population & Country & Allergists per head of population \\
\hline Argentina & $1: 46,353$ & Lebanon & $1: 121,000$ \\
\hline Belgium & $1: 900,000$ & Mexico & $1: 175,000$ \\
\hline Brazil & $1: 100,000$ & Mongolia & $1: 2,250,001$ \\
\hline Bulgaria & $1: 106,250$ & Paraguay & $1: 200,000$ \\
\hline Canada & $1: 200,000$ & Peru & $1: 1,360,000$ \\
\hline Chile & $1: 500,000$ & Portugal & $1: 63,334$ \\
\hline Colombia & $1: 571,428$ & Romania & $1: 197,577$ \\
\hline Czech Republic & $1: 17,543$ & Sebia/Montenegro & $1: 500,000$ \\
\hline Denmark & $1: 135,000$ & South Afica & $1: 1,666,666$ \\
\hline Ecuador & $1: 2,400,000$ & Spain & $1: 44,000$ \\
\hline El Salvador & $1: 470,000$ & Sweden & $1: 42,857$ \\
\hline Finland & $1: 94,545$ & Switzerland & $1: 36,649$ \\
\hline France & $1: 1,240,000$ & Turgey & $1: 1,076,923$ \\
\hline Germany & $1: 16,000$ & United Kingdom & $1: 1,083,333$ \\
\hline Greece & $1: 183,333$ & Ukraine & $1: 94,441$ \\
\hline Honduras & $1: 1,380,000$ & Uruguay & $1: 110,000$ \\
\hline Hungary & $1: 50,000$ & United States & $1: 65,546$ \\
\hline Israel & $1: 52,000$ & Venezuela & $1: 109,090$ \\
\hline Italy & 1:43,200 & & \\
\hline
\end{tabular}

Data adapted from ref 2. Permission granted by S Karger AG, Basel.

strolling with his wife after he had eaten at a buffet. He was hospitalised for severe anaphylactic shock with hypotension, requiring intramuscular adrenaline, intravenous steroids and anti-histamines. This naturally caused the patient much anxiety and he was on a very restrictive diet. He had no follow -up for his suspected allergies and was never prescribed an adrenaline auto-injector, the therapy of choice for treating another potential life-threatening event. At his recent attendance, skin prick testing was positive to various wheat -containing foods and serum specific IgE levels to wheat and omega-5-gliadin were very high. He was diagnosed with wheat -dependent exercise-induced anaphylaxis and was advised to avoid wheat and other co-factors. An emergency treatment plan and adrenaline auto-injector were prescribed. No further episodes of anaphylaxis have occurred since the appropriate avoidance measures were instituted.

Exercise induced anaphylaxis was first described 37 years ago. ${ }^{37}$ If the patient had come under the care of an allergist when he first presented with his symptoms, he could have been saved a lot of anxiety, life-threatening events due to the lack of diagnosis and appropriate preventative education and treatment, and unnecessary visits to an over-stretched public healthcare system.

Case 2: A 15-year-old boy had been receiving monthly carboplatin treatment for his recurrent hypothalamic pilocytic astrocytoma at a public hospital. During his $5^{\text {th }}$ maintenance cycle, and 90 minutes after taking aprepitant for prevention of vomiting, he was awakened by facial angioedema, conjunctival injection, upper body flushing, chest tightness and nasal congestion during the carboplatin infusion. Symptoms resolved after stopping the infusion and administration of inhaled salbutamol with intravenous chlorpheniramine and hydrocortisone. Serum tryptase measured one hour after the onset of allergic reaction rose to 5.3 microgram/L from 2.8 microgram/L, suggestive of drug-related anaphylaxis. ${ }^{38}$

The patient was initially labelled as having developed allergies to both carboplatin and aprepitant. Carboplatin, which was the first-line drug for his brain tumor, was stopped and a second-line chemotherapeutic regimen was considered.

Advice from the hospital's paediatric allergy team was obtained and the patient underwent allergy testing to carboplatin, which showed no reactivity to skin prick $(10 \mathrm{mg} /$ $\mathrm{mL}$ ) but had a $4-\mathrm{mm}$ increase in wheal size and $20-\mathrm{mm}$ flare from carboplatin intradermal injection $(1 \mathrm{mg} / \mathrm{mL})$.

The patient was desensitised to carboplatin in the Paediatric Intensive Care Unit according to a previously published 12 -step protocol. ${ }^{39} \mathrm{He}$ initially tolerated the desensitization well, but during administration of the last infusion bag he developed similar (although less intense) symptoms as his first reaction. He was eventually successfully desensitised after his protocol was lengthened to 14 steps and he has been receiving the revised regimen safely in the Paediatric Ambulatory Care Unit 
on a monthly basis.

This case exemplifies the role that an allergist can play in the management of a patient with drug allergy. If the allergy team had not been involved in his care, the patient would not have received his anti-cancer treatment of choice.

Case 3: A 24-year-old man with atopic dermatitis and food allergies had attended the Paediatric Allergy Clinic in a public hospital since childhood. He originally had cow's milk, egg and nut allergies. When his skin prick tests to milk and egg revealed reducing reactivity to both foods, he was subjected to oral food challenges which were negative and he has subsequently tolerated the foods. However, he continued to have severe allergies to peanut and tree nuts and experienced allergic reactions requiring the use of his adrenaline auto -injector after accidental ingestion. More recently, he had been having worsening eczema and frequent skin infections which would have been best managed by admission to the hospital to be treated following a well-established protocol. ${ }^{40}$ However, the paediatric ward only accepts patients $\leq 18$ years old and there is no adult allergy service, so the patient has to receive suboptimal skin care in the outpatient setting.

The Paediatric Allergy team can no longer supervise his care as an adult and he does not have the resources to see a private adult allergist so he is left in limbo. This is a problem that arises only too frequently when there is no network, as in Hong Kong, to care for allergic children once they outgrow their paediatric health providers.

\section{Recruitment from overseas}

One way to grow a discipline is to recruit specialists from overseas. ${ }^{1}$ In 2016, a public hospital in Hong Kong recruited an American board certified general paediatrician and combined adult and paediatric allergist/immunologist from the United States. However, he has to spend another 4 to 5 more years fulfilling the requirements of the Hong Kong Medical Registration Ordinance and local specialty registration with a focus on non-allergy related clinical duties before he will be recognised as a specialist in Hong Kong. This delay creates a significant obstacle for recruitment from overseas and there is a well-justified debate on whether Hong Kong should have a mechanism to recognise the qualifications of these fully trained specialists more rapidly, especially those with expertise that can fulfill an unmet need. ${ }^{41-43}$

\section{Realignment of resources}

It was also suggested earlier that it may be possible to create a new allergy service by realigning some resources, ${ }^{1}$ as numerous studies have shown that the disease-modifying treatment of allergen-specific subcutaneous injection immunotherapy is associated with substantial cost savings in health care. ${ }^{44}$ However, this strategy can be an obstacle because of competing priorities, so it is encouraging that in 2017 two public hospitals in Hong Kong have established new penicillin allergy testing services. One of the services has already made a significant impact. It was confirmed that beta-lactam drug allergies were often over-diagnosed; leading to unnecessary avoidance, increased medical costs and use of less effective antibiotic therapies. More than $90 \%$ of the patients tested so far for a beta-lactam allergy by skin and provocation testing did not have drug allergy and their false allergy labels could be removed.

The two new services are operated by a Respiratory Medicine specialist and the Immunology and Allergy trainee under supervision, respectively. They had both gained experience in testing for drug allergies at an Allergy Centre in a private hospital in Hong Kong supervised by an accredited Allergist. This example of collaboration between the private and public sectors could provide a template for future progress.

\section{Training and academic developments}

In a long overdue development, Hong Kong now has its first trainee in adult Immunology and Allergy in 20 years, so there is a total of 5 trainees undergoing allergy training currently. There is also a specialist in Rheumatology who is interested in allergy and will spend a few months in the UK in 2017 to receive allergy training. While this bodes well for the future growth of the specialty, it is slow and more trainees are required, especially in adult allergy.

The trainee in adult Immunology and Allergy obtained permission from the Hong Kong College of Physicians (HKCP) to visit overseas Centres for parts of his training to maximise his exposure to Allergy as there were no approved allergy trainers in Hong Kong. The earliest time the current trainee can be considered as a trainer himself in Immunology and Allergy is 2021, when he will be Hong Kong's only formally approved adult allergy trainer if he continues to work in an approved Centre. While acknowledging there are significant advantages to be gained from overseas training, it would be ideal if Hong Kong could also develop mechanisms to enhance local opportunities to help train future allergists. This might include recruiting allergists in private practice to become official trainers. There is a precedent already as the Hong Kong College of Family Physicians enlists private General Practitioners to help deliver parts of their training programme.

Allergy is a major component of the training curriculum of both the specialties of Immunology and Allergy under the HKCP and PIID under the Hong Kong College of Paediatricians. As allergic patients comprise a large proportion of the daily clinical practice of PIID subspecialists, the subspecialty board of PIID has applied to change the name of the subspecialty to "Paediatric Immunology, Allergy and Infectious Diseases" (PIAID). The impact of this visionary decision, if approved, on securing the future of paediatric allergy as a discipline in Hong Kong cannot be overemphasized.

\section{Professional societies and patient organisations}

The Hong Kong community is well supported by allergy related professional societies and patient organisations. These include the Hong Kong Institute of Allergy (HKIA), Hong Kong Society of Paediatric Respirology and Allergy (HKSPRA), Hong Kong Society of Paediatric Immunology Allergy and Infectious Diseases (HKPIAID), Hong Kong Allergy Association (HKAA) and Hong Kong Asthma Society (HKAS). They all host allergy conventions, symposia and courses. They publish position papers and clinical allergy practice guidelines. ${ }^{3,45,46}$ They have their own websites and some of them have social media platforms to engage the 
public. They publish regular newsletters. HKIA also offers scholarships for members to train overseas and provides travel grants to attend allergy conferences. A new competitive research grant scheme was launched in 2016.

Two patient organisations, namely HKAA and HKAS, are committed to making a difference to patient experience through peer-group support, patient and public education, advocacy, and organisation of social activities.

The HKAA was founded in 2008 by individuals with allergic disorders, their care-givers and medical professionals as a tax-exempted charity. It organises regular educational events for its members and peer-group sharing. The Association also offers out-reach programs to schools, teaching teachers how to use adrenaline auto-injectors. Funding was obtained from the government to employ a full-time staff member and rent a permanent premise at a relatively low cost. The premise was converted into an Education Centre and commenced its service in 2017.

The HKAS was established in 1989. This group provides services for asthma and allergy sufferers as well as their families so that they can better manage their condition. With the support of the Hong Kong Thoracic Society and the HKSPRA, the HKAS also offers medical advice to its members.

\section{Discussion and recommendations}

The creation of a flourishing allergy service has become increasingly pressing with the rising prevalence of allergic diseases and the strong emerging evidence that suggests there could be ways to prevent development of allergy, including the early introduction of allergenic foods to infants. ${ }^{3,4-6,16,17,47-52}$ However, the logistic difficulties and resource implications for implementing early introduction of peanut (let alone multiple foods) to prevent allergy are enormously challenging even for countries that are well served by allergists. ${ }^{53}$ Hong Kong and many countries in the Asia Pacific are simply not equipped in terms of expertise, manpower and facilities to test the new hypotheses comprehensively or to take advantage of these major public health advances in allergy.

While it is encouraging to note that a few of the suggestions proposed in $2015^{1}$ to improve allergy provision and training in Hong Kong have been accomplished, it is disappointing that the major proposal to establish Allergy Centres of Excellence is far from being achieved in any public hospital.

Centres of Excellence provide an integrated 'hub' of multi -professional allergy expertise. They have many advantages. They can provide much needed seamless transitional care to children with allergic diseases as they grow into adulthood. They conduct world leading research in the discipline. They can be a structured framework to plan staffing and resource allocation in the specialty. They coordinate teaching of allergy to undergraduates and postgraduates, and they develop transparent career paths and integrative exit strategies for trainees. They can provide outreach clinical services, train doctors and allied health professionals in primary and secondary care (the 'spokes') and raise the professional and public profile for the discipline.

Many patients with asthma, eczema and rhinosinusitis are currently being treated by specialists in Respiratory Medicine,
Dermatology and Otolaryngology, respectively, and a Centre of Excellence in allergy is not intended to compete with specialists in these and other disciplines. To the contrary, successful Centres are trans-disciplinary and should be collaborating with colleagues to provide integrated and holistic care for complex patients who are often characterised by multisystem involvement.

Future interactions between Allergy Centres with other disciplines could be facilitated by defining the types of patients that would require specialised intervention and management by a Centre of Excellence in allergy. These criteria could be guided by those recommended by the UK's National Health Service Commissioning Clinical Reference Group $^{54}$ and include patients with increased risk of death because of the severity of their allergic condition (e.g. drug allergy, anaphylaxis, angioedema, brittle asthma), persisting poor quality of life with a major allergic component despite routine therapies, requirement for allergen immunotherapy, rare diseases leading to allergic symptoms requiring complex investigations and therapies (e.g. mastocytosis, hypereosinophilic disorders, hereditary angioedema) and diseases with allergic symptoms but where the cause is unclear requiring input by specialists to make a specific diagnosis, identify triggers, optimise management and prevent further recurrences.

The hub-and-spoke model for Allergy Centres was adopted by the UK in $2007^{55}$ and a pilot Centre was subsequently created. Each of the two medical schools with their partner hospitals in Hong Kong has the core of an allergy and immunology service already. It would not require a lot of resources to transform each of them into a Centre of Excellence. The imminent opening of a Children's Hospital also provides an opportunity to integrate various strands of paediatric allergy and immunology expertise into a Centre of Excellence. Before and after these Centres are created, service provision in allergy might be further improved by creatively establishing new clinics through realignment or sharing of resources.

An international survey ${ }^{2}$ revealed that the ratio of allergists per head of population in countries that are best represented by allergists is 1 allergist: $<100,000$ heads of population. Likewise in Hong Kong, most of the main medical specialties are also similarly serviced. ${ }^{33}$ Thus, Hong Kong will require at least 70 allergists for a population of around 7 million if it is to approximate other medical disciplines locally and to be close to the best international standards. There are about 4.5 fold more adults than children in Hong Kong, so this equates to a minimum target of 16 (FTE) paediatric allergists and 54 (FTE) adult allergists.

The current lack of any adult allergy trainers in Hong Kong is an impediment to building a thriving clinical service. While acknowledging the benefits of gaining experience overseas, more consideration could be given on how to improve the local training environment, for example, by outreach to private allergists. Meanwhile, it will be essential to formulate a transparent exit strategy for the current batch of allergy trainees so that their career progression is an exemplar to other potential trainees who could be inspired to join the programme. 
It would be helpful if a more expeditious mechanism for registration for overseas trained doctors in Hong Kong can be agreed so that they can be assimilated into Hong Kong's health care system more quickly in the face of ensuring high professional standards, especially those with expertise that can fulfill an unmet need such as allergy.

Finally, educating the profession and engaging the public about allergy and its prevention are urgently required. Introduction of changes, for example, to traditional infant feeding habits will require a seismic shift in professional practice as well as a change in societal culture and behaviour.

\section{Conclusion}

The public and professional profile of allergy in Hong Kong has increased in the last few years. The community is well supported by professional societies and patient orientated patient organisations. The numbers of allergists have grown slightly. Two new drug allergy clinics have been established de novo in public hospitals. However, Hong Kong still has an unmet need for allergy specialists and is ill equipped to exploit recently discovered public health opportunities to prevent allergy.

The specialty can be helped to grow by recruiting suitably trained allergists from overseas and by realignment of resources to create new services. Recruitment from overseas would be facilitated by shortening the process for the assimilation of recruits into Hong Kong's healthcare system.

It is our strong recommendation that at least two Centres of Excellence in allergy are established in Hong Kong, with their many clinical and academic advantages, to lead the drive towards reaching the goal of having one allergy specialist serving 100,000 heads of population.

Finally, engagement of the profession and the public about allergy is fundamental to any proposed strategy to develop the discipline.

\section{References}

1 Chan YT, Ho HK, Lai CKW, Lau CS, Lau YL, Lee TH, et al. Allergy in Hong Kong: an unmet need in service provision and training Hong Kong Med J. 2015;21:52-60.

2 Warner JO, Kaliner MA, Crisci CD, Del Giacco S, Frew AJ, Liu GH, et al. World Allergy Organization Specialty and Training Council. Allergy practice worldwide: a report by the World Allergy Organization Specialty and Training Council. Int Arch Allergy Immunol. 2006;139:166-74.

3 Chan AWM, Chan JKC, Tam AFC, Leung TF, Lee TH. Guidelines for allergy prevention in Hong Kong. Hong Kong Med J. 2016;22:279-85.

4. Schäfer T, Bauer CP, Beyer K, Bufe A, Friedrich F, Gieler U, et al. S3 -Guideline on allergy prevention 2014 update: Guideline of the German Society for Allergology and Clinical Immunology [DGAKI] and the German Society for Pediatric and Adolescent Medicine [DGKJ]. Allergo J Int. 2014;23:186-99.

5. Fewtrell, M, Bronsky J, Campoy C, Domellof M, Embleton N, Fidler Mis N, et al. Complementary Feeding: A Position Paper by the European Society for Paediatric Gastroenterology, Hepatology, and Nutrition (ESPGHAN) Committee on Nutrition. J Pediatr Gastroenterol Nutr. 2017;64:119-32.

6. Togias A, Copper SF, Acebal ML, Assaad A, Baker JR, Beck LA, et al. Addendum guidelines for the prevention of peanut allergy in the United States: Report of the National Institute of Allergy and Infectious Diseases-sponsored expert panel. J Allergy Clin Immunol. 2017;139:29-44.

7. Wong GWK, Leung TF, Ko WS Changing prevalence of allergic diseases in the Asia -Pacific region. Allergy Asthma Immunol Res. 2013;5(5):251-7.

8. Romagnani S. The increased prevalence of allergy and the hygiene hypothesis: missing immune deviation, reduced immune suppression, or both? Immunology. 2004;112:352-63.
9. Strachan DP. Family size, infection and atopy: the first decade of the "hygiene hypothesis". Thorax. 2000;55 Supp 1:S2-10.

10. Woodfolk JA, Platts-Mills TA. The immune response to intrinsic and extrinsic allergens: determinants of allergic disease. Int Arch Allergy Immunol. 2002;129:277-85.

11. von Mutius E, Braun-Fahrländer C, Schierl R, Riedler J, Ehlermann S, Maisch S, et al. Exposure to endotoxin or other bacterial components might protect against the development of atopy. Clin Exp Allergy. 2000;30: 1230-4.

12. World Health Organisation. Media Centre: Infant and young child feeding [Internet]. Geneva: World Health Organisation; c2017[cited 2017 Aug 21]. Available from: http://www.who.int/mediacentre/factsheets/fs342/en/587

13. American Academy of Pediatrics, Committee on Nutrition. Hypoallergenic Infant Formulas. Pediatrics. 2000;106:346-9

14. Greer FR, Sicherer SH, Burks AW. Effects of early nutritional interventions on the development of atopic disease in infants and children: the role of maternal dietary restriction, breastfeeding, timing of introduction of complementary foods, and hydrolysed formulas. Paediatrics. 2008;121:183 -91 .

15. Koplin JJ, Allen KJ Optimal timing for solids introduction - why are guidelines always changing? Clin Exp Allergy. 2013;43:826-34.

16. Du Toit G, Roberts G, Sayre PH, Bahnson HT, Radulovic S, Santos AF, Brough HA,et al ; LEAP Study Team. Randomized trial of peanut consumption in infants at risk for peanut allergy. N Engl J Med. 2015; 372(9):803-13.

17. Perkin MR, Logan K, Tseng A, Raji B, Ayis S, Peacock J, et al. Randomized trial of introduction of allergenic foods in breast-fed infants. N Engl J Med. 2016;374:1733-43.

18. Wong GWK Preventing food allergy in infancy - early consumption or avoidance? New Eng J Med. 2016;374:783-4.

19. Natsume O, Kabashima S, Nakazato J, Yamamoto-Hanada K, Narita M, Kondo M, et al. Two-step egg introduction for prevention 613 of egg allergy in high-risk infants with eczema (PETIT): a randomised, 614 double-blind, placebo-controlled trial. Lancet. 2017;389(10066):276-86.

20. Wei-Liang Tan J, Valerio C, Barnes EH, Turner PJ, Van Asperen PA, Kakakios AM, et al. A randomized trial of egg introduction from 4 months of age in infants at risk for egg allergy. J Allergy Clin Immunol. 2017;139(5):1621-8.

21. Palmer DJ, Sullivan TR, Gold MS, Prescott SL, Makrides M. Randomized controlled trial of early regular egg intake to prevent egg allergy. J Allergy Clin Immunol. 2017;139(5):1600-7.

22. Bellach J, Schwarz V, Ahrens B, Trendelenburg V, Aksünger Ö, Kalb B,et al. Randomized placebo-controlled trial of hen's egg consumption for primary prevention in infants. J Allergy Clin Immunol. 2017;139(5):1591-9.

23. du Toit G, Tsakok T, Lack S, Lack G. Prevention of food allergy. J Allergy Clin Immunol. 2016;137(4):998-1010.

24. Horimukai K, Morita K, Narita M, Kondo M, Kitazawa H, Nozaki M, et al. Application of moisturizer to neonates prevents development of atopic dermatitis. J Allergy Clin Immunol. 2014;134(4):824-30.

25. Tham EH, Lee BW, Chan YH, Loo EX, Toh JY, Goh A, et al. Low food allergy prevalence despite delayed introduction of allergenic foods Data from the GUSTO cohort. J Allergy Clin Immunol Pract [preprint]. 2017 [cited 2017 August 21]. Available from: https://doi.org/10.1016/ j.jaip.2017.06.001

26. Forrest KY, Stuhldreher WL. Prevalence and correlates of vitamin D deficiency in US adults. Nutr Res. 2011;31(1):48-54.

27. A Spiro, Buttriss JL Vitamin D: An overview of vitamin D status and intake in Europe. Nutr Bull. 2014;39(4):322-50.

28. Yang HK, Choi J, Kim WK, Lee SY, Park YM, Han MY, et al. The association between hypovitaminosis D and pediatric allergic diseases: A Korean nationwide population-based study. Allergy Asthma Proc. 2016;37(4):64-9.

29. Baek JH, Shin YH, Chung IH, Kim HJ, Yoo EG, Yoon JW, et al. The link between serum vitamin $\mathrm{D}$ level, sensitization to food allergens, and the severity of atopic dermatitis in infancy. J Pediatr. 2014;165(4):849-54.

30. Wang SS, Hon KL, Kong AP, Pong HN, Wong GW, Leung TF. Vitamin D deficiency is associated with diagnosis and severity of childhood atopic dermatitis. Pediatr Allergy Immunol. 2014;25(1):30-5.

31. Wang SS, Hon KL, Kong AP, Tang MF, Sy HY, Chan JC, et al. Eczema phenotypes are associated with multiple vitamin D pathway genes in Chinese children. Allergy. 2014;69(1):118-24.

32. Yao TC, Tu YL, Chang SW, Tsai HJ, Gu PW, Ning HC,et al. Suboptima vitamin D status in a population-based study of Asian children: prevalence and relation to allergic diseases and atopy. PLoS One. 2014;9(6):e99105. 
33. The Medical Council of Hong Kong. List of Registered Medical Practitioners [Internet]. Hong Kong: The Medical Council of Hong Kong. c2016- [cited 2017 Aug 22]. Available from: https://www.mchk.org.hk/ english/list_register/specialist_list.php

34. Lee TH, Ho HK, Leung TF Can Hong Kong take advantage of recent advances to prevent allergies? Hong Kong Medical J. 2017;23:539-40.

35. Statistics Times. List of Countries by Projected GDP per capita [Internet]. [place unknown]: Statistic Times. c2016 [cited 2017 Aug 21]. Available from: http://statisticstimes.com/economy/countries-by=prjected-gdp-capit a.php

36. Lo A. Hong Kong powers ahead, but its people have been left behind. South China Morning Post. Comment. Insight and Opinion. c2017 [cited 2017 August 21]. Available from: http://www.scmp.com/print/comment /insight-opinion/article/2104687/hong-kong-powers-ahead-its-people -have-been-left-behind

37. Sheffer AL, Austen KF. Exercise-induced anaphylaxis. J Allergy Clin Immunol. 1980 Aug;66(2):106-11.

38. Waterfield T, Dyer E, Wilson K. How to interpret mast cell tests. Arch Dis Child Educ Pract Ed. 2016 Oct;101(5):246-51.

39. Lee CW, Matulonis UA, Castells MC. Carboplatin hypersensitivity: a 6-h 12-step protocol effective in 35 desensitizations in patients with gynecological malignancies and mast cell/IgE-mediated reactions. Gynecol Oncol. 2004 Nov;95(2):370-6.

40. Lee SI, Kim J, Han Y, Ahn K. A proposal: Atopic Dermatitis Organizer (ADO) guideline for children. Asia Pac Allergy. 2011 Jul;1(2):53-63.

41. GovHK. LCQ9: Non-locally trained doctors practising in Hong Kong [Internet]. c2016- [cited 2017 Aug 21]. Available from: http://www.info.gov. HK/gia/general/201601/20/P201601200538.htm

42. Jones C. Hurdles for foreign-trained doctors in Hong Kong reveal double standards[Internet]. Hong Kong; South China Morning Post; 2017[cited 2017 Aug 21]. Available from: http://www.scmp.com/print/comment/insig ht-opinion/article/1760234/hurdles-foreign-trained-doctors-hong-kong -reveal-double

43. Lo A. Hong Kong needs to open the door to foreign doctors[Internet]. Hong Kong; South China Morning Post; 2017 [cited 2017 Jun 9]. Available from: http://www.scmp.com/comment/insight-opinion/article/2062950/hong -kong-needs-open-door-foreign-doctors
44. Lockey F, Hankin CS Health economics of allergen-specific immunotherapy in the United States J Allergy Clin Immunol. 2010;127:39-43.

45. Lee TH, Chan J, Lau VWY, Lee WL, Lau PC, Lo MH. Immunotherapy for peanut allergy. Hong Kong Med J. 2014;20:325-30.

46. Lee $\mathrm{TH}$, Wu YY, Chan JKC, Ho HK, Li PH, Rosa Duque JS Immunoglobulin $\mathrm{G}$ ( $\mathrm{IgG}$ ) testing in the diagnosis of food allergy and intolerance. Hong Kong Med J.2017;23(4):419-20.

47. von Berg A, Filipiak-Pittroff B, Schulz H, Hoffmann U, Link E, Sußmann $\mathrm{M}$, et al. Allergic manifestation 15 years after early intervention with hydrolyzed formulas - the GINI Study. Allergy. 2016;71:210-9.

48. de Silva D, Geromi M, Halken S, Host A, Panesar SS, Muraro A, et al Primary prevention of food allergy in children and adults: systematic review. Allergy. 2014;69:581-9.

49. Grimshaw KE, Maskell J, Oliver EM, Morris RC, Foote KD, Mills EN, et al. Diet and food allergy development during infancy: birth cohort study findings using prospective food diary data. J Allergy Clin Immunol. 2014; 133:511-9.

50. Nwaru BI, Erkkola M, Ahonen S, Kaila M, Haapala AM, Kronberg- Kippilä $\mathrm{C}$, et al. Age at the introduction of solid foods during the first year and allergic sensitization at age 5 years. Pediatrics. 2010;125:50-9.

51. Palmer DJ, Sullivan TR, Gold MS, Prescott SL, Makrides M. Randomized controlled trial of early regular egg intake to prevent egg allergy. J Allergy Clin Immunol. 2017;139:1600- 7.

52. Koplin JJ, Osborne NJ, Wake M, Martin PE, Gurrin LC, Robinson MN et al. Can early introduction of egg prevent egg allergy in infants? A population-based study. J Allergy Clin Immunol. 2010;126:807-13.

53. Koplin JJ, Peters RL, Dharmage SC, Gurrin L, Tang ML, Ponsonby AL, et al. Understanding the feasibility and implications of implementing early peanut introduction for prevention of peanut allergy. J Allergy Clin Immunol. . 2016;138(4):1131-41.

54. NHS Commissioning Board. B09/S/b 2013/14 NHS Standard Contract for Specialised Allergy Services (all ages)[Internet]. Leeds; NHS England; 2013. [cited 2017 Aug 21]. Available from: https://www.england.nhs.uk/wp -content/uploads/2013/06/b09-spec-allergy.pdf

55. House of Lords Science and Technology Committee. Allergy: HL 166-I 6th Report of Session 2006-07 - Volume 1. London: The Stationery Office Ltd; 2007. 